\title{
LA CONSTITUCIÓN NARRATIVA DE LA SUBJETIVIDAD MORAL
}

\author{
Gerard Vilar \\ (Universitat Autònoma de Barcelona)
}

Con toda razón, Descartes es recordado y celebrado por ser el genial matemático, físico y fisiólogo, el revolucionario fundador de la modema filosofia del sujeto y la consciencia, y en fin el gran transformador de la filosofia en método. Sin embargo, se le recuerda menos como escritor, y ello pese a ser, tras Montaigne, el fundador de la moderna literatura filosófica francesa, una tradición que siempre ha sabido reunir el rigor conceptual con la fuerza literaria, entretejer la argumentación con la narración y la creación en el medio de la palabra. El Discurso o las Meditaciones son monumentos literarios en los que Descartes es capaz de arrastrarnos e introducirnos en su vida o en sus meditaciones como un novelista nos arrebata e introduce en su mundo ficticio de acontecimientos, personajes y pasiones. Si consideramos la obra de Descartes por este lado literario, entonces el célebre ego desencarnado y autónomo, que se permite dudar de todo y reconstruir metódicamente el conocimiento de lo verdadero, del saber claro y distinto, se nos presenta a un tiempo bajo un aspecto completamente otro, esto es, también como el sujeto escritor o el narrador, capaz de fabular mundos dominados por demonios malignos que intentarian hacernos creer en ilusiones, o capaz de reconstruir su identidad presentando una autobiografia. El racionalismo metódico del sujeto epistémico aparece, asi, acompañado por la narratividad de un sujeto que constituye su identidad en el contar sus propias andanzas a la búsqueda de la verdad y la felicidad, al modo como lo hiciera Montaigne en sus célebres Essais. Esta segunda dimensión de la subjetividad, bien patente en la filosofia teorética cartesiana, ya no puede entenderse solamente en términos de la autonomía cognitiva o práctica del ego, sino que debe también entenderse en términos de autenticidad expresiva. Acnso donde más claro se vea el punto de reunión de estos dos registros, sea en la filosofia práctica cartesiana, en la que la morale par provision sintetiza la lógica de la autonomía con la lógica de la autenticidad.

La noción de sujeto, es cierto, domina la fïlosofia teórica moderna y contemporánea, pero ello es más cierto aún si cabe en la filosofia práctica -asi como la estética. Pues las ideas de un sujeto moral autónomo y responsable y de un ciudadano libre son los temas del pensamiento ético y politico de esta época. Sólo que no lo han sido de la misma manera. Asi, el periodo comprendido entre el fin del Renacimiento y el presente se puede dividir en tres grandes etapas:

I) Constitución de la categoria normativa de sujeto y de los conceptos con que éste se piensa (libertad, autonomía, responsabilidad, interés, consciencia moral, igualdad, derechos, sentimientos, etc.). Esta gran etapa cubre el periodo que va del Renacimiento a la llustración, digamos de Montaigne a Kant y Ficlite.

II) La segunda etapa es la del descenramiento del sujeto, de critica de la moral y la polilica centrada en la noción de sujeto autónomo y autotransparente. Este periodo comprende las tentativas de socavar el sujeto (a menudo en nombre de un sujeto todavia no existente) desde Hegel y Marx hasta $A$ dorno, Foucault y Derrida.

III) La última y' más reciente ctapa es la de la reconstrucción y rehabilitación de la subjetividad normativa, una etapa que se inicia en los años sesenta y en la que destacan nombres como los de Parlit, Rawls y Habermas o, con otras estrategias teóricas, Rorty y Taylor. 
Vamos a demorarnos un momento en comentar algunos aspectos del proceso general de constitución de la subjetividad en la filosofia práctica para luego centrarnos en la opción narrativa. Continuaré comentando algunos aspectos de las nociones de autonomia y autenticidad y, por fin, terminaré reafirmando la propuesta de lectura de Descartes con la que iniciaba mi intervención.

\section{La constitución de la subjetividad normativa}

La primera etapa de la filosofĩa práctica moderna aparece como notablemente colerente en lo que se refiere al denominador común de la defensa de la subjetividad moral, politica y jurídica. Esta subjetividad nace con el debilitamiento de las estructuras politicas y sociales medievales y, muy especialmente, de aquella cosmovisión religiosa que dominó el mundo durante mil años. Los modernos habitantes de la ciudad creen cada vez menos en un orden moral y politico inmutable del mundo garantizado por Dios y sancionado por la Iglesia. Este mundo en el que la corrupción de la curia papal es denunciada por Savonarola y Lutero, en el que Roma cs saqueada por Carlos V, el mundo de la Reforma y la Contrarreforma, de redefinición de los poderes del Príncipe $y$ de formación del Estado moderno, es un mundo en el que el individuo ha perdido las certezas y se halla confrontado a su propia subjetividad, en el que tiene que reconsiderar el lugar que ocupa, su relación con el todo, con la comunidad. Su pregunta fundamental, que ya no podremos eludir de hecho las generaciones posteriores, fue ¿por qué hemos de ser morales, si ya no hay sanción divina ni garantias para el juicio ni la acción? La categoría filosófica principal de esta época, será, entonces, la de autonomia, es decir, la capacidad del individuo de pensar y decidir por si mismo en asuntos prácticos. También en el mundo antiguo tuvo la autonomia una importancia central, pero puesto que jamás se pensó en los individuos como unidades desgajables de la totalidad de la polis o la comunidad, la autonomia era pensada más bien hacia el interior de los individuos, como autogobierno y automodelación de la naturaleza interior de cada uno y, por tanto, como libertad frente a las pasiones $y$ los deseos. Los modernos, en cambio, piensan más bien la autonomia hacia el exterior, como independencia de la comunidad, de las constricciones que impone vida en sociedad $y$, por tanto, como libertad frente a la naturaleza exterior para elegir la propia vida, el propio camino a la felicidad.

Pero la naturaleza de esta subjetividad moral es pensada de muy distintas maneras y elaborada conceptualmente con estrategias intelectuales extrañas entrc si. En tan breve tiempo sólo puede intentarse un esbozo bastante grosero de lo que deberia exponerse y argumentarse con mucha más precisión. Un esbozo de esta naturaleza, sin embargo, debe distinguir, si más no, tres lineas diferentes, aunque no excluyentes, de abordaje de la constitución filosófica de la subjetividad normativa, a saber: la via del individualismo posesivo de Hobbes y Locke; la via del universalismo de la consciencia de Rousseau y Kant; y, por último, la vía de la constitución narrativa al modo de Montaigne. A esta última es a la que vamos a prestar atención.

\section{Subjetividad y narratividad}

En la obra de Montaigne (1533-92), en sus Ensayos y en su Diario de viaje encontramus el paradigma de la constitución narrativa de la subjetividad. Aunque era un católico creyente, Montaigne creia que en realidad la moralidad no podia provenir y fundamentarse en una fuente de autoridad exterior al hombre mismo. Sus conocimientos de la tilosofia práctica clásica y sus experiencias de la vida pública y mundana (fue miembro del parlamento y alcalde de Burdeos) le llevaron a la convicción de que ningún modelo de vida buena ni ningún sistema de creencias podía satisfacer las necesidades de guia de los hombres de su tiempo; ni siquiera 
la doctrina cristiana, después del cisma protestante, podia ofrecer estándares a una mayoria de las personas. Montaigne sugirió que en este mundo asolado por guerras continuas, por conflictos doctrinales y de intereses, cada cual debe encontrar su camino personal en la vida ensayando la conciliación de las ideas y las realidades con unas buenas dosis de escepticismo y estoicismo. Montaigne nos ofreció además su propio ejemplo personal en su obra, en la que los esfuerzos del pensador por realizar el ideal clásico de una vida consciente en el mundo moderno dieron como resultado un monumento literario y filosótico.

"Pintome a mi mismo", nos advierte Montaigne en el proemio de sus Essais, "yo mismo soy la materia de mi libro". ' Este es un arduo trabajo que le lleva a convertirse en centro de gravedad de su propia vida: "Desde hace varios anos que soy el único objetivo de mis pensamientos, que no analizo y estudio más que mi propia persona: y si estudio otra cosa, es para aplicarla al pronto sobre mi, o mejor dicho, aplicármela a mí... No hay descripción de tanta dificultad como la de uno mismo, ni ciertamente de tanta utilidad" (II, vi, 63 s.). "El mundo mira siempre hacia fuera; repliego yo la vista hacia mi interior, fijola y ocúpola alli. Cada cual mira de frente; yo miro dentro de mi: sólo he de habérmelas conmigo, analizome sin cesar, contrólome y pruébome" (II, xvii, 408). Pero lariamos muy mal en juzgar como mero viaje al interior esa concentración del escritor filosófico en sí mismo. No tiene nada de ensimismamiento o repliegue romántico al modo del "alma bella" goethiana o novaliana. "Mi oficio y mi arte es vivir" (id.) escribe. Asi en su libro, a través, de su yo, encontramos un fresco imponente y original de su época, de sus costumbres y sus temores - asi como también de los tiempos pasados.

El hombre Montaigne vive en "un siglo desbordado" (III, ix, 195), y es consciente plenamente de que su logorrea se debe al estado de turbulencias y descomposición de su época — “cuándo escribimos tanto como desde que vivimos en estos disturbios?” (id.). Como un sabio antiguo busca con todo su autonomia: "quiero ser maestro de mi mismo, en todos los sentidos" (III, v, 68). En este proyecto de poseerse a sí mismo en este tiempo desbordado la elaboración de sus ensayos ocupa un lugar fundamental. Pero ¿qué clase de subjetividad es la que se constituye en la narración y la reflexión escrita dia a día en los Essais y en el Diario de viaje? Se trata de una subjetividad fluida, de una subjetividad tejida en el curso de los acontecimientos diarios, como un "objeto informe" que a duras penas puede meter en ese "cuerpo etéreo de la palabra" (II, v, 64). No estamos, por consiguiente, ante un equivalente del sujeto gnoseológico cartesiano, firme fundamento del razonamiento idéntico siempre a sí mismo y capaz de dar con las ideas claras $y$ distintas. La identidad narrativa montaigniana es una identidad fluidificada en el tiempo, en los acontecimientos, en las relaciones con los otros seres humanos y, no en último lugar, en la constitución de un texto que es una colección de ensay'os, de tientos, de pruebas, en el que se integra la voz del pasado a través de las constantes citas del libro de los libros, de los poetas, y de los denás escritores del mundo antiguo. "No pinto el ser", escribe en el ensayo sobre el arrepentimiento, "pinto el paso: no el paso de una edad a otra o, como dice el pueblo, de siete anos en siete años, sino dia a dia, minuto a minuto. He de adaptar mi historia al momento. Podré cambiar dentro de poco no sólo de fortuna sino también de intención. Es un registro de diversos y cambiantes hechos y de ideas indecisas cuando no contrarias; ya sea porque soy otro yo mismo, ya porcuue considere los temas por otras circunstancias y en otros aspectos" (III, ii, 26 s.).

1 M. DE MONTAIGNE, Ensạıos, Madrid: Cátedra, 1992, vot. I. p. 35. 
El proyecto de Montaigne, puede entenderse, pues, como el de una autoposesión narraiva. Este yo fluido en un mundo permanentemente mutable sólo puede atraparse en el tejido $\longrightarrow$ lexto- de la propia narración. El yo y su narración devienen entonces una unidad indisoluble: "No he hecho mi libro más de lo que mi libro me ha hecho; libro consustancial a su autor, mediante tarea propia, parte de mi vida; no mediante una tarea y una meta tercera y ajena como todos los demás libros" (1Il, xviii, 416). La tarea narrativa se ha convertido asi en la larea de la identidad del sujeto Montaigne: "Todos me reconocen en mi libro y a mi libro en mi" (III, v, 112). Cada cual es, por consiguiente, su propio texto. I'ero, ¿puede haber entonces dos textos iguales? ¿Si somos diferentes puede haber una moral para todos, $y$ un orden político justo para todos? Desde luego, Montaige hace el voto renacentista de $\mathrm{fe}$ en la htmanitas: "Cada hombre encierra la forma entera de la condición humana" (III, ii, 26). Pero el problema fillosófico de la universalidad queda en Montaigne completamente abierto. No parece que haya lugar en ese autor para una razón práctica en sentido fuerte, sino sólo para un buen juicio, para una prudencia sólo articulable racionalmente de modo narrativo.

Rousseau en sus Confesiones y en Las ensoñaciones del paseante solitario practicó, más allá de las obvias diferencias, el mismo tipo de ensayo que fundara Montaigne. Kierkegaard continuó de modo consecuente, en otro contexto cultural e histórico, esta exploración de la subjetividad tipicamente moderna que, con mayor frecuencia, visitarán como es lógico los escritores y en la que encontramos obras cumbres de la literatura como lida y poesia de Goethe, la Recherche proustiana o las cinco novelas autobiográficas de Bernhard. Por lo demás, este modo de comprensión de la subjetividad práctica no es incompatible con otros modos de entender filosóficamente la identidad práctica del sujeto moderno. Como después argumentaré con más detalle, aun cuando Descartes sea el fundador de la moderna filosotia del sujeto y de la consciencia, en su obra entretejió la narración de sus andanzas y sus propios descubrimientos filosóficos con su argumentación objetiva acerca de la consciencia como fundamento último del saber, $y$ ello de un modo acaso nunca más igualado posteriormente. Pensemos, asimismo, que J.S. Mill en su Autobiografia o Collingwood en la suya fueron continuadores de esta tradición digamos mixta.

Esta compatibilidad probablemente laya venido favorecida por el hecho de que ningún yo puede ser auténticamente centrado y lijado narrativamente $y$, por tanto, aquellos que han padecido alguna forma de lo que se ha llamado "ansiedad cartesiana" por pensar el sujeto como un centro, algo firme y estable, han tenido que buscar necesariamente otras vias alternativas o complementarias de constitución de la identidad además de la narración. Este último caso es el de Descartes.

\section{Autonomia $y$ autenticidad}

La filosofia moderna y contemporánea ha encontrado en la tarea de definir la difusa noción de autonomía una de las empresas más complejas y ricas de todos los tiempos, una tarca que es a un tiempo de autodefinición de ser lumano o de persona, con todas las implicaciones antropológicas, juridicas, politicas y éticas que tal empresa tiene. Un riquísimo vocabulario cae en avalancha sobre cualquiera que se plantee diclia empresa. Para proseguir la argumentación, permitanme que les proponga una pequeĩa geogralia conceptual. En general llamamos autonomia al principio de pensar con la propia cabeza, se servirse del propio entendimiento y de no dar por cierto nada que no hayamos pensado por nosotros mismos, aunque cllo tampoco sea garantía luego de estar en lo cierto. Esta es Ia intuición básica que sobre lodo la llustración puso en circulación y que hoy pertenece al sentido común. 
En la filosofia normativa contemporánea el concepto de autonomia la sido delinido de muy distintas maneras en función del tipo de perspectiva. Todo lo cual ha dado lugar a un amplio vocabulario, a un rico léxico en el que no es nada fäcil orientarse. Por ejemplo, H. Frankfurt, $\mathrm{G}$. Dworkin o $\mathrm{A}$. Domenecl definen la autonomia como la capacidad de segundo orden de las personas para reflexionar criticamente acerca de sus preferencias, deseos, apetencias, creencias, etc., de primer orden y la capacidad de aceplar o intentar cannbiarlas a la luz de preferencias y valores de orden superior. $\Lambda$ qui nos encontramos ante un concepto epistemico. Esta explicación del concepto de autonomía da cuenta de la dimensión cognitiva y racionalformal de la conducta autónoma poniendo énfasis en la componente de automodelación en el sentido de la capacidad para el autogobierno, el autoconocimiento, el autocontrol, la autoelección, etc., que sin duda forman parte de una existencia autónoma. Dificilmente puede ser autónoma aquella persona que sea esclava de sus prejuicios, de sus pasiones o viva en permanente conflicto entre creencias o preferencias contradictorias.

Otra concepción fundantental de las que dominan el escenario fïlosófico contemporáneo es el concepto normativo autonomia descrito como superación del punto de vista egocéntrico, es decir, autonomia como capacidad de situarse en un punto de vista general, desinteresado, imparcial, el a menudo llamado "punto de vista moral". Este es el concepto que Kant desarrolló como centro de su ética y que recoge la dimensión estrictamente moral de la vida autónoma: es autónoma aquella voluntad que se deja vincular al interés general, aun cuando podria decidir hacer lo contrario. La autonomía entendida cono autovinculación al punto de vista moral, el punto de vista de lo que todos podrian querer se erige en punto de vista racional. Sin embargo de esta concepción se han presentado modelos muy distintos según el enfoque sea individualista, esto es, planteado desde alguna forma de filosofia de la consciencia y del sujeto, como en el caso paradigmático de Kant, o bien según un enfoque holista o intersubjetivo al modo de las tiorias de Apel o liabermas, por citar otros ejemplos conocidos. En el primer caso la autonomia es entendida monológicamente, esto es, básicamente como autodeterminación de un sujeto libre y descomprometido que en la soledad de su consciencia delibera y decide acerca de lo moralmente bueno. En el segundo caso, la autonomia es entendida dialógicamente, esto es, como responsabilidad discursiva - en alemản, la Zurec/mungsfahigkeit - o capacidad de dar cuenta discursivamente de las propias opiniones y acciones y de participar en discursos prácticos a la búsqueda de aquellas normas que expresan los intereses generalizables.

Una tercera concepción es la que podriamos denominar éstética. En el esteticismo helenizante del último Foucault (1987) o en el ironismo rortyano, por referirnos a los ejemplos recientes más llamativos, la autonomia se presenta como ética individual gue rechaza someterse a cualquier clase de normas, ya sean éstas normas a priori, normas contractuales o consensuadas, y cuyo sentido es el de hacer de la propia vida una obra de arte. El concepto estetizante de autonomia como autocreación o autoestilizacion más allia del bien y del mal, como obrar que genera su propia normatividad y constiluye su propia unidad de sentido (o muestra la imposibilidad de la misma), recoge una dimensión no menos fundanental que el anterior de la autonomía vivida por los modernos. Desde que en el Renacimiento surgiera el modelo de humanidad del héroe cuya vida alcanza la eternidad por sul carácter singular y ejemplar - como las obras de arte- pasando por el genio romaintico y el esteta linisecular o postmoderno. en el imaginario civilizatorio occidental de la modernidad ha sido recurrente encontrar imagenes estetizantes de una existencia autónoma. $Y$ grandes pensiluores como Goethe, llumboldt, Marx o Mill recogieron en sus obras este concepto, aunque siempre en 
tensión con la segunda de las concepciones de la autonomia, la normativa. Sólo con el esteticismo que se inicia con Baudelaire y Nietzsche se perdió esta fundamental conexión con la dimensión normativa.

No obstante, la modernidad ha dado lugar a otras categorias para pensar la difusa noción de autonomia. Autenticidad o soberania son algunas de ellas. Autenticidad es acaso la más conocida, dada la importancia que que tiene en la cultura americana como "filosofia espontánea" de la cosa, exportada a todos los rincones del planeta, $y$, muy en segundo término, a la difusión que la filosofia existencialista le dio en el tercio central del siglo $\mathrm{xx}$ hasta quedar incorporada al sentido común occidental. Que uno sea libre, justo o autónomo no es nada obvio, acaso quimérico. Pero todo el mundo está de acuerdo en que al menos se puede ser auténtico y que, aunque la verdadera libertad y la veradera rectitud quizás no estén al alcance de nuestra mano, al menos podemos empeỉamos en su búsqueda de un modo auténtico. Incluso es algo comúnmente aceptado que cada cual, como un pequeno Yalivé, tiene derecho a ser o devenir auténticamente el que es. La autenticidad, sin embargo, es una categoria de difícil encaje en las grandes tendencias que presentábamos, pues no es sólo una categoría epistémica, o sólo normativa o sólo estética, sino que reúne todas esas facetas, si bien parece insuficiente sobre todo en relación a la dimensión normativa.

\section{Descartes entre Ia autonomia y la autenticidad}

La moral provisional cartesiana se plantea en un doble registro: afirmando por un lado una lógica de la autonomia, $y$, por otro lado, afirmando una lógica de la autenticidad. La lógica de la autonomia viene afirmada sobre todo por el carácter general de la moral par provision misma. puesto que se trata de un conjunto de reglas provisionales para la conducta que laan de guiar a los individuos en tanto no se alcance una moral autenticamente fundada en conocimientos claros, precisos y distintos. Pero la noción de autonomia está implicada especilicamente en la primera y la tercera reglas de moral.

La primera de ellas es sintetizada por Descartes en su carta del 4 de agosto de 1645 a Ia princesa Elisabeth de Bohemia. Cualquiera, sostiene Descartes, puede hallar el contento sin esperar nada más "siempre que trate de servirse, lo mejor posible, de su espiritu, para conocer lo que debe hacer o no hacer en todas las situaciones de la vida". Se trata del principio socrático clásico de que la virtud es conocimiento y que sólo el libre ejercicio de nuestras capacidades intelectuales puede ser garantia para realizar el bien y alcanzar la felicidad: "No determinándose nuestra voluntad a seguir o evitar alguna cosa, sino porque nuestro entendimiento se la representa como buena o mala, basta juzgar bien para obrar bien, y juzgar lo mejor posible para hacer también lo mejor". De todos modos, en el Discurso del método Descartes añade algunas cosas más al mero ejercicio abstracto del "espiritu": propone especificar una regla de prudencia de cuño aristotélico que apunta a evitar los extremos, propone también seguir las costumbres del propio pais aceptadas por las personas más sensatas, $y$, por fin, no enajenarse jamás la propia libertad de pensamiento y acción por medio de votos o contratos que obliguen a perseverar en algo anteriormente elegido, a fin de no privarse de la propia autonomía que tiene que ser el fundamento de la moral.

Si la primera regla pone el acento en la autonomia frente a las falsas ideas, prejuicios o conocimientos poco seguros, es decir, en la autonomia teorética o intelectual, la tercera regla, en cambio, pone el acento en la autonomía frente a las propias pasiones, deseos, necesidades e instintos, es decir, en la autonomía práctica entendida en el sentido clásico como autosuficiencia, autogobierno o automodelación y que explícitamente remonta a la sabiduria de los filóso- 
fos antiguos que supieron "sustraerse al imperio de la fortuna y competir en felicidad con los dioses" alterando sus deseos y eligiéndose a sí mismos. "Mi tercera máxima, escribe Descartes, fue siempre vencerme a mi mismo antes que a la fortuna y alterar mis deseos antes que el orden del mundo; y acostumbrarme a creer que sólo nuestros pensamientos están enteramente en nuestro poder, de manera que, después de haber obrado lo mejor que hemos podido, en lo tocante a las cosas exteriores, lo que no logramos es absolutamente imposible para nusotros. $Y$ esto por si solo me parecia bastante para impedirme desear en el porvenir nada que no pudiese adquirir y mantenerme contento".

Sin embargo, Descartes recuerda continuamente, como hiciera Montaigne, la fragilidad de las cosas humanas, las limitaciones de la razón y las urgencias de la breve vida de los seres humanos. Nada es más revelador en este sentido que el final de las. Meditaciones donde se dice que "puesto que la necesidad de los asuntos de la vida nos obliga a menudo a tomar una determinación antes de que hayamos tenido la oportunidad de examinarlos con suficiente detenimiento, hay que reconocer que la vida del hombre está sujeta a fracasar muy a menudo en las cosas particulares; $y$ en fin hay que reconocer la falta de firmeza y la debilidad de nuestra naturaleza". Ante esta fragilidad, Descartes apuesta por otro registro, el que llamábamos la lógica de la autenticidad. Ya que el ejercicio de la autonomia no es ninguna garantía de acierto, lo que al menos si podemos ser es, sostiene Descartes, ser auténticos. La segunda de las reglas de la moral apunta sobre todo esto. "Ser lo más firme y resuelto que pudiese en mis acciones y seguir con tanta constancia en las opiniones más dudosas, una vez resuelto a ello, como si fueran muy seguras... Y como muchas veces las acciones de la vida no admilen demora, es una verdad muy cierta que, cuando no está en nuestro poder discernir las opiniones más verdaderas, debemos seguir las más probables; $y$, aunque no hallemos mayor probabilidad en unas que en otras, debemos, sin embargo, decidirnos por algunas y considerarlas después, en cuanto referidas a la práctica, no como dudosas, sino como muy verdaderas y ciertas, ya que lo es la razón que nos ha determinado a seguirlas. $Y$ esto fue bastante, termina escribiendo Descartes, para librarme, desde entonces, de todos los arrepentimientos y remordimientos que suelen agitar las conciencias de esos espíritus débiles y vacilantes que con tanta inconstancia practican como buenas cosas que después consideran malas".

Es por la lógica de la autenticidad que Descartes no nos presenta su método de indagación y sus reglas prácticas como el verdadero y único método, por más que él mismo aspirara a que esa fuera la naturaleza de sus descubrimientos. Quiero recordar que al comienzo mismo del Discurso Descartes realizn la célebre afirmación de que sus reflexiones sólo tienen carácter ejemplar y apelativo: "No es, pues, mi propósito enseñar aqui, dice, el mélodo que cada cual debe seguir para dirigir bien su razón, sino sólo exponer de qué manera lie tratado de conducir la mia." Esta afirmación del carácter apelativo de la validez del método es subray'ada aún más por Descartes al hacer la sorprendente afirmación, normalmente tenida por un gesto de modestia y un modo de captar la benevolencia del lector, de que al cabo se trata de una fábula: "Como yo propongo, dice, este escrito tan sólo a modo de historia o, si se prefiere, de fäbula, en la que entre algunos ejemplos que se pueden imitar quizá se hallen otros muchos que sería razonable no seguir, espero que será útil para algunos sin ser nocivo para nadie y que todos agradecerán mi franqueza".

Pero la franqueza no es garantia de verdad o de validez general. En la ética cartesiana no parece que haya lugar para una universalidad como la buscada en el conocimiento matemático o médico. Podemos aqui repetir lo dicho anteriormente a propisito de Montaigne, a saber que no hay un claro lugar en este autor para una razón prictica en sentido fuerte, sino sólo para un 
buen juicio, para una prudencia sólo articulable razonablemente de modo narrativo. No se puede equiparar, ciertamente, el proyecto de Montaigne, mucho más puro en su orientación narrativa, сол el de Descartes, cuya ambigiedad siempre dará que hablar y que escribir. Aquí sólo se ha tratado de subrayar la ambivalencia del discurso y de la razón cartesianos. Sólo se ha intentado hacer ver que método, argumento y narración se hallan estrechamente unidos en su obra. Que la búsqueda de la felicidad desde el presupuesto de la autonomía es a un tiempo un esfuerzo por la autenticidad y que ambas lógicas se entretejen para formar esa compleja figura del espiritu moderno que son esos textos que llamamos "Descartes" y en los que no podemos dejar de reconocernos. 